\title{
Density and Morphological Properties of Some Reinforced Polymers
}

\author{
${ }^{1}$ P.A.P. Mamza* and ${ }^{2}$ B.T. Nwufo \\ ${ }^{1}$ Department of Chemistry, Ahmadu Bello University, Zaria. Nigeria. \\ ${ }^{2 .}$ Department of Chemistry, University of Jos, Nigeria. \\ [*Corresponding Author's email: mamzapaul@yahoo.com]
}

\begin{abstract}
The morphology of some reinforced blends of Polystyrene (PS) and Polyvinyl Acetate (PVAc) were estimated by density measurements, showing a definite pattern except that the filler composition increases the densities of the blends with 30/70, 20/80 and 10/90, PS/PVAc having highest values than other compositions. Also, photomicrographs of the different blends show a two phase system appearing bright (PVAc phase) and the other appearing black (PS phase) in virtually all the micrographs, even though the heterogeneity due to phase inversions is relevant for some compositions. For some composition a domain distribution shows considerable miscibility within the range of compositions.
\end{abstract}

KEYWORDS: Phase inversions, domain distribution, miscibility, phase system.

\section{INTRODUCTION}

Mechanical and viscometric studies on blends of polystyrene $\{$ PS $\}$ and Polyvinyl acetate $\{$ PVAc $\}$ had been reported earlier (Mamza and Folaranmi, 1996;Mamza and Nwufo, 2008) revealing compatibility domains along composition ranges. Also, the swelling behaviour of these blends in different solvents and the effects of filler on the electrical conductivity was reported earlier (Mamza and Nwufo, 2008). Three techniques are widely used to measure densities of polymer sample, these include density gradient column, dilatometry and pycnometry (Tager, 1978). Densities of melted crystallized polymers of semicrystallized polymers are based on two phase systems (crystalline and amorphous) and each phase may be characterized by a unique density (Sheldon, 1963; Wunderlich 1973). It can be shown that, the weight fraction crystallinity can be expressed as a function of density. In this work the BS 2782 part 6 method is used, while the morphological arrangements of the blends were studied by Scanning Electron Microscopy.

\section{EXPERIMENTAL METHODS}

Density Measurement of the PS/PVAc Blends The density of the blends (both virgin and reinforced) was measured as mass per unit volume, according to BS 2782 part 6. Graphs were plotted of density of unfilled and filled PS/PVAC blend versus blend compositions.
Establishment of Blend Morphologies of the Ps/Pva ${ }_{c}$ Blends

The morphologies of the cross-section of the blend of different compositions with or without the filler incorporated in the polymer-polymer matrix were examined by Scanning Electron Microscope N.J.F (SEM, Jeol, JSM-840 SEM) at magnification of $1000 \mathrm{X}$ (at the Department of Metallurgical Engineering, Ahmadu Bello University, Zaria).

\section{RESULTS AND DISCUSSION}

Effect of Filler Composition on the Density of the PS/PVA ${ }_{C}$ Blends

Figure 1.0 show the variation of density of the virgin and reinforced PS/PVAC blends with blend compositions. The trend is similar in both the blends except that the filler increase the density of the blends and that in $30 / 70 \%$, $20 / 80 \%$ and $10 / 90 \%$ PS/PVA $A_{C}$ the densities are higher than the other compositions. Matsuaka (1961) reported that density is a measure of order within a polymer and hence it is evident that the level of interaction and compatibility seem to be higher in these three blend compositions. The densities increase slightly for 90/10\% and 80/20\%, PS/PVA ${ }_{\mathrm{C}}$ and decreases sharply for $70 / 30 \%, 60 / 40 \% 50 / 50 \% \mathrm{PS} \mathrm{PVA}_{\mathrm{C}}$ blends increasing, again for $40 / 60 \%$ PS/PVA and more pronounced in the case of $30 / 70 \%$, 
20/80\% and 10/90\% PS/PVA ${ }_{C}$ blends. The rise in density is attributable to the fillings of the inherent voids within polymer-polymer matrix by the filler particles. Since it is established that voids are domains of zero density and hence, a high density polymer will have low voids content.

Morphological Studies on the PS/PVA $\mathbf{C}$ Blends $\begin{array}{lllll}\text { Figure } 2.0 & \text { to } & 2.19 & \text { show the }\end{array}$ photomicrographs of the different blends of PS/PVAc with and without the $\square$-cellulose filler loadings. They all show two phase systems, bright poly(vinylacetate) phase and black Polystyrene phase. Large macrodomain of the polyvinyl acetate appear to be dispersed in the dark phase of the Polystyrene. Likewise, Polyvinylacetate phase engulfs polystyrene phase. For compositions 70/30, 60/40, 50/50 40/60 and 30/70, PS/PVAc, (with and without filler) i.e.

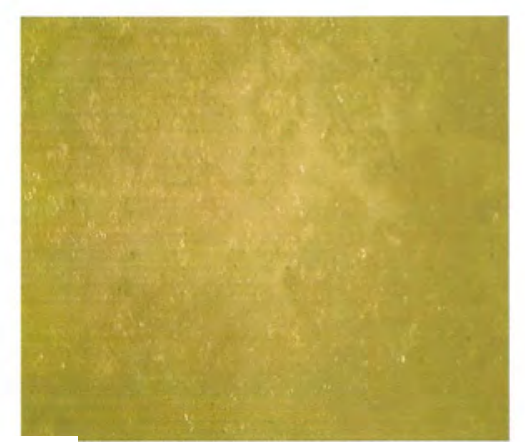

Fig. 2.0 Photomicrograph of $10 \% \mathrm{PS} / 90 \%$ PVAC blend without filler

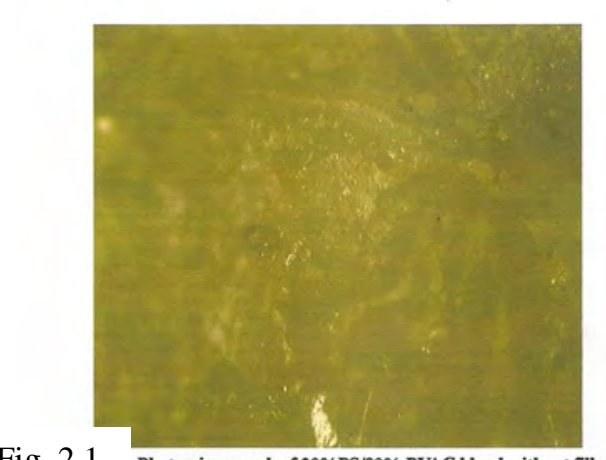

Fig. 2.1 Photomicrograph of $20 \% \mathrm{PS} / 80 \%$ PVAC blend without filler

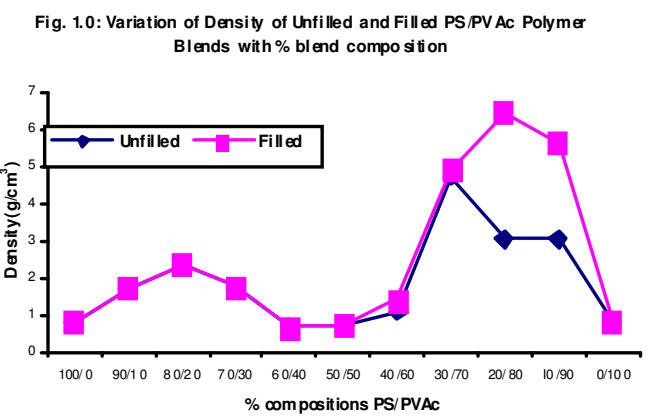

Figures 2.3, 2.4, 2.5, 2.6, 2.7, 2.8, 2.9, 2.13, 2.14, 2.15 , and 2.16 there's apparent show of heterogeneity of phases which reveals the level of immiscibility of Poly(vinyl Acetate) with Polystyrene at these compositions. This phenomenon is indicative of phase inversions. However, blends of compositions 80/20, 10/90, 20/80 and 90/10 PS/PVAc i.e. Figures 2.0, 2.1, $2.2,2.16,2.17,2.18$ and 2.19 show a considerable miscibility due to a domain distribution in these ranges of compositions.

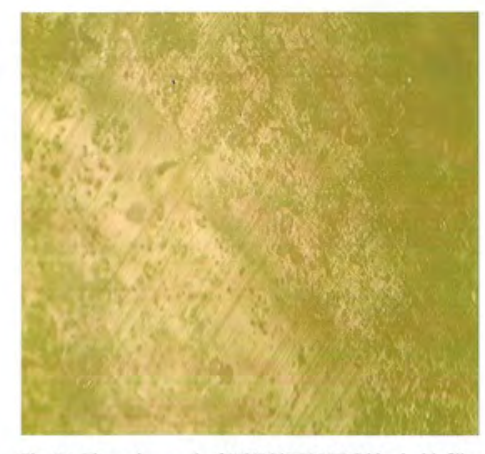

Fig. 2.2

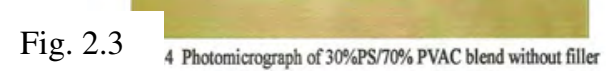




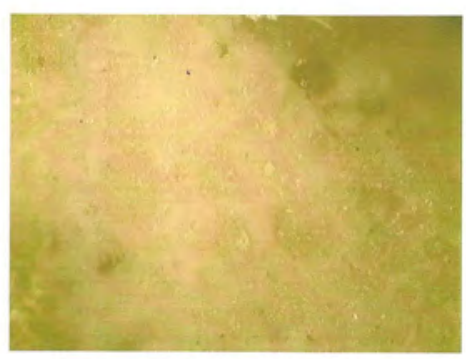

Fig. 2.4 5 Photomicrograph of $30 \% \mathrm{PS} / 70 \%$ PVAC blend with filler

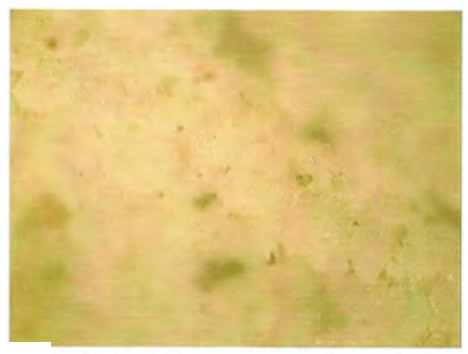

Fig. 2.5 Photomicrograph of $40 \% \mathrm{PS} / 60 \%$ PVAC blend without filler

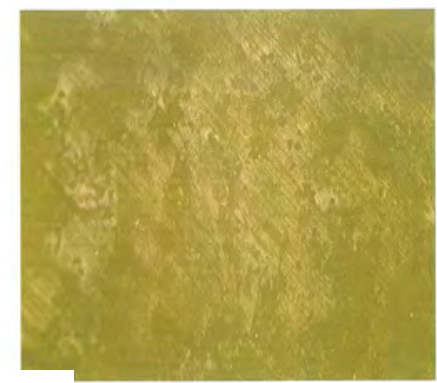

Fig. 2.6 Photomicrograph of 40\%:PS/ $/ 00 \%$ PVAC blend with filler

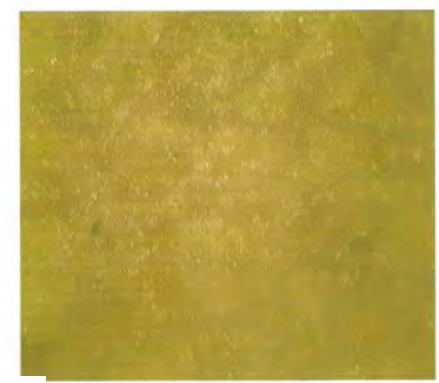

Fig. 2.7 Photomicrograph of 50\% $\mathrm{PS} / 50 \%$ PVAC blend without filler

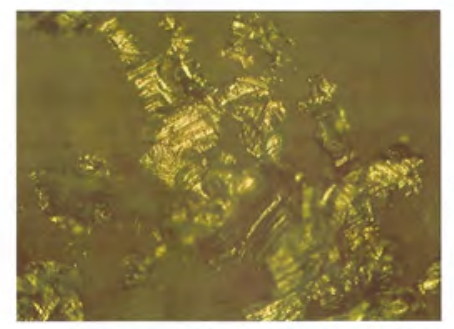

Fig. 2.8

Photomicrograph of 50\% $1 \mathrm{PS} / 50 \%$ PVAC blend with filler

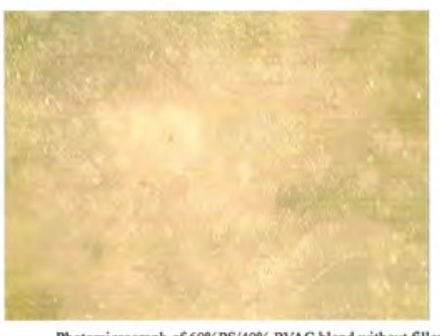

Fig. 2.9

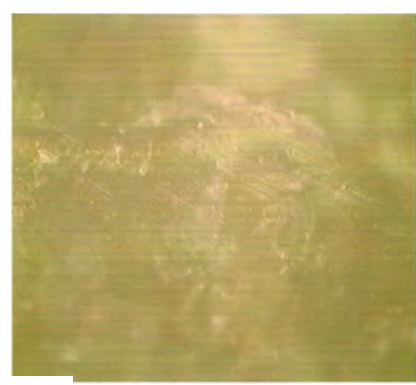

Fig. 2.10 Photomicrograph of $60 \%$ PS $40 \%$ PVAC blend with filler

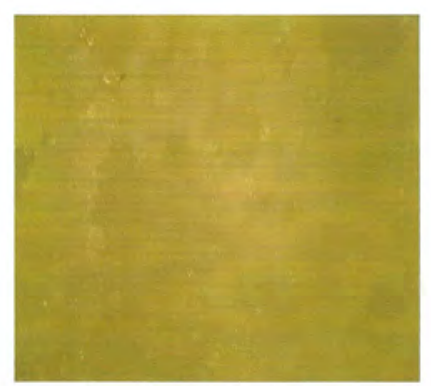

Fig. 2.11 hotomicrograph of 70\% $10 \mathrm{PS} / 30 \%$ PVAC blend without filler 


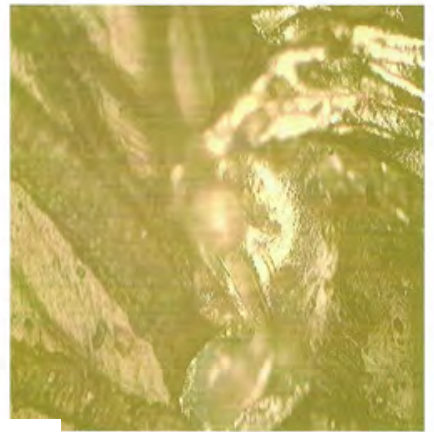

Fig.2.12

Photomicrograph of $70 \% \mathrm{PS} / 30 \%$ PVAC blend with filler

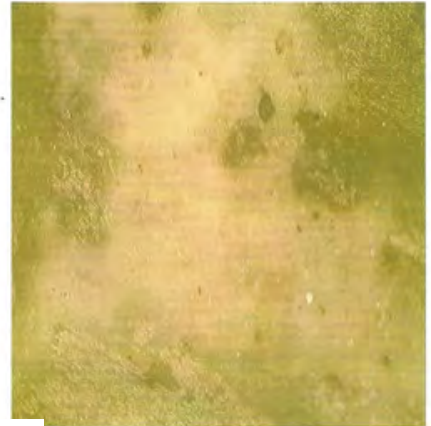

Fig. 2.13

1. Photomicrograph of $80 \% \mathrm{PS} / 20 \%$ PVAC blend without filler

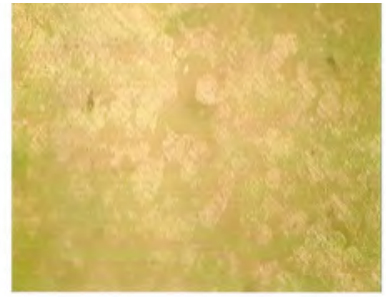

Fig. 2.14

Photomicrograph of $80 \%$ PS/20\% PVAC blend with fill

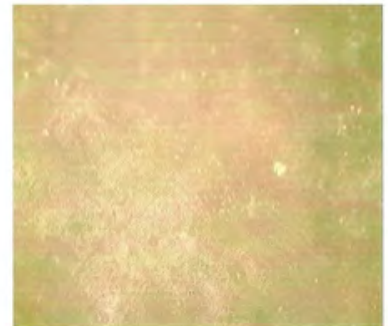

Fig. 2.15

Photomicrograph of 90\%:PS/10\% PVAC blend without filler

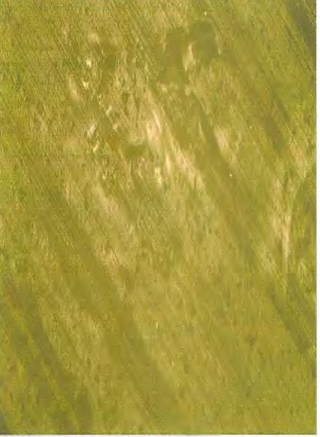

Fig. 2.16 Photomicrograph of 90\%:P/10\% PVAC blend with filler

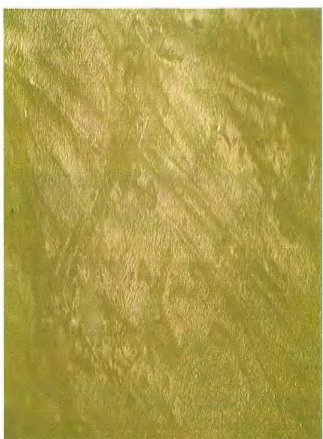

Fig. 2.17 Photomicrograph of $100 \%$ PS without filler

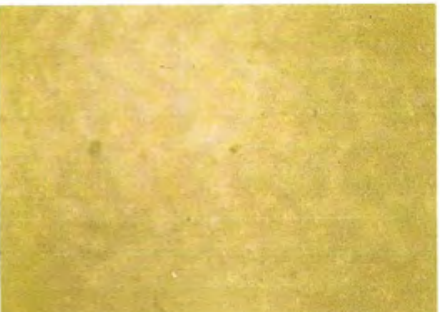

Fig.2.18 Photomicrograph of $100 \%$ PVAC with filler

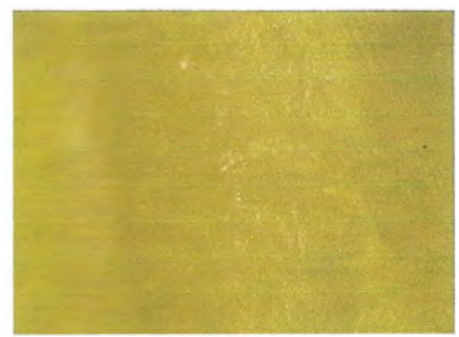

Fig. 2.19 Photomicrograph of $100 \%$ PVAC without filler 


\section{CONCLUSION}

The Density and Morphological studies carried out on the blends had established the level of micro-structural arrangements in the polymerpolymer matrixes, under the effect of $\alpha$-cellulose filler and had shown that structure-property relationships are essential aspect of Polymer blend Technology through proper end -use applications in the industries.

\section{REFERENCES}

Tager, A. (1978). Physical Chemistry of Polymers, Mir Publishers Moscow, $2^{\text {nd }}$ Edition.

Sheldon, R.P. (1963). Density and Degree of Crystallinity, Polymer Lett. 1: 655 - 657.

Wunderlich, B. (1963), Motion in the Solid State of High Polymers, J. Polymer Sci. 41.
Matsuoka, S, (1961). Hypothesis of voids in semi-crystalline Polymers, J. Appl. Phys. 32: 2334-2336.

Mamza, P.A.P. and Folaranmi, F.M. (1996). Compatibility studies on solution of Polystyrene and Polyvinyl acetate blend by density and viscometric methods, Eur. Polymer J. 32(7): 909-912.

Mamza, P. A. P. and Nwufo, B. T. (2008). Effect of filler composition on the structure/property relationships in polystyrene and polyvinyl acetate blends. Adv. Polymer Technol. \{in press .

Mamza, P.A.P. and Nwufo, B.T. (2008). The swelling Behaviour of Polystyrene $\{\mathrm{PS}\} /$ Polyvinyl acetate $\{$ PVAc $\}$ blends in different solvents and the effects of $\alpha$ cellulose used as a filler on the Electrical conductivity. Nig. J. Basic Appl. Sci. 16(2): 161-165. 